Fortnightly Review

\title{
Diagnosis and treatment of systemic lupus erythematosus
}

\author{
Patrick J W Venables
}

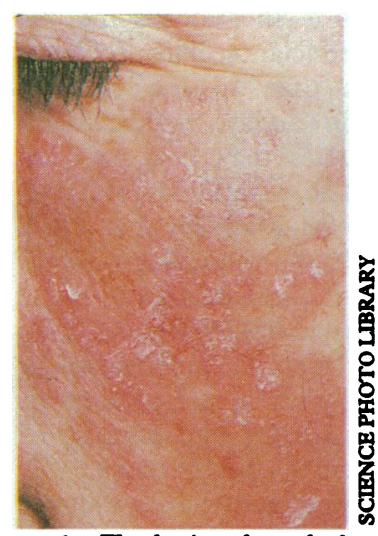

FTG 1-The classic malar rash of systemic lupus erythematosus. Although virtually diagmostic, it occurs in only about $50 \%$ of parients
Kennedy Institute of Rheumatology, London W6 7DW

Patrick J W Venables, senior lecturer

BMY 1993;307:663-6
The definitive diagnosis of a disease depends on knowledge either of its aetiology or on recognition of a unique pattern of clinical features. Neither applies to systemic lupus erythematosus. Its aetiology is unknown and many of its clinical features such as arthritis, vasculitis, and serositis are shared by other autoimmune rheumatic diseases. Although the well known wolverine rash (fig 1) from which lupus derives its name is relatively specific, it occurs in only about $50 \%$ of patients. The variability of clinical features has prompted a search for a specific laboratory investigation. The lupus erythematosus cell phenomenon described in 1948 and the DNA antibody test described in 1968 were each thought in their time to provide the answer. Subsequent experience has shown that, like the clinical features, the autoantibodies are heterogeneous. ${ }^{1}$ Nevertheless their definition has done much to improve diagnostic accuracy, provide information about subsets of the disease, and delineate related syndromes overlapping with systemic lupus erythematosus.

\section{Diagnostic clinical features}

The evaluation of diagnostic criteria, ${ }^{2}$ intended primarily for classification of patients for research, has also done much to formalise the recognition of patterns that constitute a clinical diagnosis. In systemic lupus erythematosus, as in most autoimmune rheumatic disease, arthritis is common. The joint disease is characteristically non-erosive and can affect both large and small joints. Peripheral joint disease is often associated with prominent periarticular and tendon involvement, which can lead to Jaccoud-like deformities superficially similar to rheumatoid arthritis, though these deformities differ in that they are correctable (fig 2). Raynaud's phenomenon occurs in

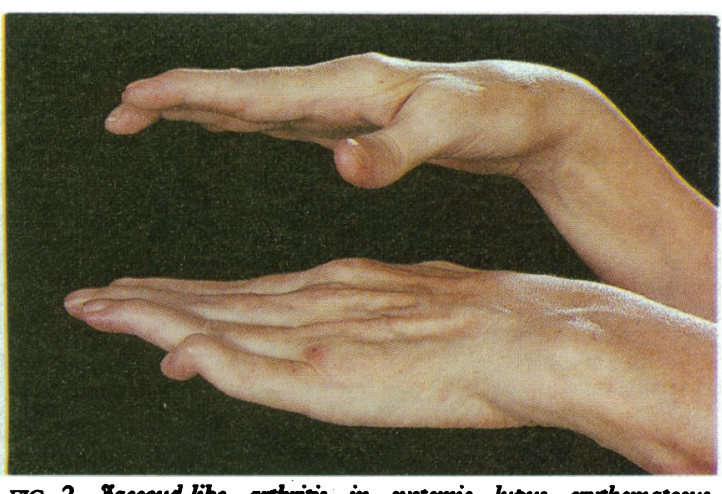

FIG 2- Yaccoud-like arthritis in systemic lupus erythematosus. Although superficially resembling theumatoid arthritis the deformities are correctable and associated with relatively little joint damage. This type of arthritis also occurs in other connective tissue diseases, particularly Sjögren's syndrome and some overlap syndromes

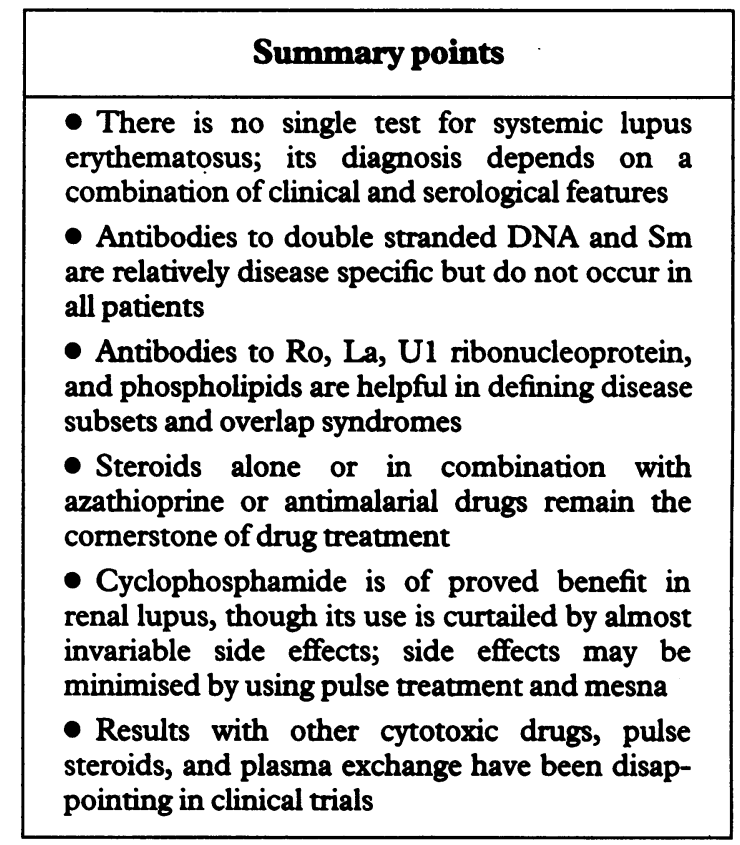

about half of patients but is more common in systemic sclerosis and many of its related overlap syndromes such as mixed connective tissue disease. Serositis, commonly manifest as pleurisy or pericarditis, occurs in about $60 \%$ of patients. Cutaneous manifestations are common and include cutaneous vasculitis, livedo reticularis, oral ulcers, and the malar rash. The highly distinctive skin lesions of discoid lupus (fig 3) and subacute cutaneous lupus erythematosus (fig 4) can occur on their own, indicating a benign form of cutaneous lupus, but can also be associated with, or later complicated by, systemic disease.

Renal disease and central nervous system involvement, reviewed by Ginzler and Antoniadis, ${ }^{3}$ are the most important factors determining prognosis. Renal disease probably complicates less than half of cases, and recent estimates of the frequency of central nervous system involvement have suggested a prevalence of $10-18 \%{ }^{3}$ Lung disease (interstitial pneumonia, obliterative bronchiolitis or fibrosing alveolitis) and muscle disease (myositis or a non-specific proximal myopathy) may also occur in lupus, though they tend to be relatively mild. More severe muscle and lung disease often points to one of the many myositis associated overlap syndromes. ${ }^{45}$

\section{Serological diagnosis}

Autoantibodies in systemic lupus erythematosus react mainly with ubiquitous cellular antigens, and the 


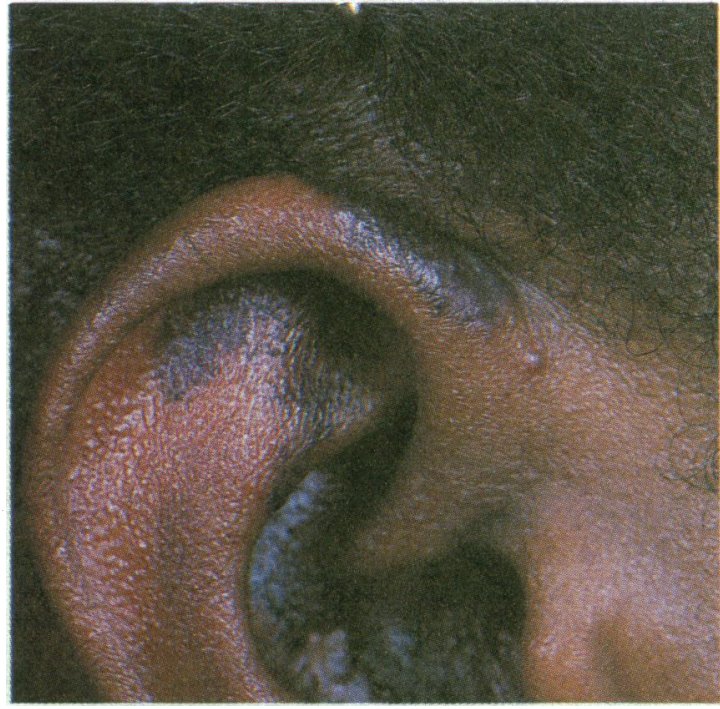

FIG 3-Discoid lupus affecting the ear as discrete hyperpigmented lesions, and the hair is patchy alopecia

disease is regarded as a prime example of non-organ specific autoimmunity. The cellular targets of the antibody response range from DNA in the nucleus to phospholipids on the cell surface, and at first sight the antibodies would seem as heterogeneous as the clinical features with which they are associated. A closer analysis has shown that the antibodies fall into three distinct groups: nucleic acids, nucleic acid binding proteins, and cell membrane antigens (table I). The nucleic acids are DNA, the nucleic acid binding proteins are histones and ribonucleoproteins, and the cell membrane antigens are phospholipids and the proteins that bind to them. The nomenclature of some of the ribonucleoprotein antigens has been confusing. $\mathrm{Ro}, \mathrm{La}$, and $\mathrm{Sm}$ antibodies were originally named after the first two letters of the names of the patients in whom they were first found. U1 ribonucleoprotein (formerly known simply as ribonucleoprotein or RNP) is so called because the antigen lies on polypeptides bound to a specific uridine rich RNA. The Sjögren's syndrome A and B antigens (SS-A and SS-B) are now known to be identical to $\mathrm{Ro}$ and $\mathrm{La}$ respectively and this has become the preferred nomenclature. Extractable nuclear antigen originally referred to a partially purified saline nuclear extract which was enriched for $\mathrm{U} 1$ ribonucleoprotein and $\mathrm{Sm}$ antigen. Now that its components have been identified, the term extractable nuclear antigen should no longer be used. The delineation of anticellullar antibodies has resulted in two aspects of clinical application: the diagnosis and the identification of disease subsets and overlap syndromes.

Most antibodies in systemic lupus erythematosus

TABLE I-Autoantibodies in diagnosis and disease subsets of systemic lupus erythematosus (SLE)

\begin{tabular}{|c|c|c|c|}
\hline Antibody & Sensitivity & Specificity & Disease subset \\
\hline \multicolumn{4}{|l|}{ DNA: } \\
\hline \multicolumn{4}{|l|}{$\begin{array}{l}\text { DsDNA } \\
\text { Ribonucleoproteins: }\end{array}$} \\
\hline UIRNP & $30 \%$ & Low & $\begin{array}{l}\text { Overlap ( - mixed connective tissue disease), Raynaud's, } \\
\text { myositis, fibrosing alveolitis }\end{array}$ \\
\hline $\mathrm{Sm}$ & $7-30 \%$ & High (marker) & Membranous nephritis \\
\hline Ro (SS-A) & $40 \%$ & Medium & $\begin{array}{l}\text { Sjögren's/SLE overlap, subacute cutaneous LE, } \\
\text { congenital heart block, membranous nephritis }\end{array}$ \\
\hline La (SS-B) & $10 \%$ & Low & $\begin{array}{l}\text { Sjögren's/SLE overlap, subacute cutaneous LE, } \\
\text { congenital heart block }\end{array}$ \\
\hline rRNP & $5-15 \%$ & Medium & Cerebral lupus (?) \\
\hline \multicolumn{4}{|l|}{ DNA binding proteins: } \\
\hline $\begin{array}{l}\text { Histones } \\
\text { Ku } \\
\text { PCNA }\end{array}$ & $\begin{array}{l}50 \% \\
>5 \% \\
>5 \%\end{array}$ & $\begin{array}{l}\text { Low } \\
\text { Medium } \\
\text { High }\end{array}$ & $\begin{array}{l}\text { Drug induced SLE } \\
\text { Sclerodactyly } \\
\text { Severe disease }\end{array}$ \\
\hline \multicolumn{4}{|l|}{ Cell membrane: } \\
\hline Cardiolipin & $20-30 \%$ & Low & Thrombosis, abortion \\
\hline
\end{tabular}

may be detected as antinuclear antibodies by indirect immunofluorescence, and hence this remains the most sensitive screening test ( $>95 \%)$. Two important antibodies, anti-Ro (SS-A) and anti-phospholipid, may be associated with a negative result on this test. It is likely-though this has not been formally tested-that testing for a combination of antinuclear, anti-Ro, and antiphospholipid antibodies would pick up more than $99 \%$ of patients. All of the antibodies to specific cellular antigens are potentially useful in diagnosis, though with varying disease sensitivity and specificity (table I). Antibodies to double stranded DNA and Sm are virtually restricted to systemic lupus erythematosus, to the extent that they have come to be called markers, but as the prevalence of antibody to DNA is $50-70 \%$ and that of antibody to $\mathrm{Sm}$ is as low as 7\% in some studies, the term marker may be misleading. Nevertheless the specificity of these antibodies is high enough to warrant their inclusion in the revised diagnostic criteria. All of the other autoantibodies in table $I$ occur in other autoimmune rheumatic diseases, but a combination is often highly suggestive of systemic lupus erythematosus. The relatively rare autoantibodies $\mathrm{Ku}$ and PCNA are useful when other standard autoantibody tests are negative results.

The association of antibodies with patterns of disease expression in systemic lupus erythematosus may be more of interest to the theoretician seeking evidence for pathogenic mechanisms than to the clinician seeking practical guidance in disease management. Nevertheless, specific antibodies may help to elicit warnings of clinical value. The association of DNA antibodies with glomerulonephritis implies that a rise in these antibodies may herald the worsening of renal function or the appearance of renal disease in some patients. The presence of phospholipid antibodies may predict thrombotic events or recurrent abortions. ${ }^{7}$ In pregnancy maternal Ro antibodies should prompt an early examination of the fetal heart rate because of the association with congenital heart block. U1 ribonucleoprotein antibodies in high titre are no longer regarded as markers of mild disease and may prompt the search for occult but potentially fatal features resembling those of mixed connective tissue disease, such as fibrosing alveolitis or polymyositis.

\section{Other laboratory tests}

The search for, and failure to discover, the holy grail of a single autoantibody test to diagnose systemic lupus erythematosus has tended to eclipse the potential value of other, simpler investigations in diagnosis. Leucopenia, particularly lymphopenia, may be found in two thirds of patients with active disease. Thrombocytopenia may be an indicator of poor prognosis, and serum creatinine concentration has been reported as the best marker of an unfavourable outcome in renal disease. ${ }^{78}$ Patients with systemic lupus erythematosus, in common with those with other autoimmune rheumatic diseases, have raised polyclonal immunoglobulin concentrations but a normal acute phase response providing there is no additional infection. The erythrocyte sedimentation rate, which is affected by serum proteins and acute phase reactants, has come to be regarded as unreliable in diagnosis, though a change may correlate well with disease activity.

Reduced serum complement concentrations are useful in diagnosis and in assessing disease áctivity. One mechanism for this is thought to be consumption by immune complexes. However direct measurement of circulating complexes, intensively investigated during the $1980 \mathrm{~s}$, has proved to be unrewarding. Assays for complement breakdown products have not been shown to be superior to simple measurements of plasma $\mathrm{C} 3$ and $\mathrm{C} 4$ concentrations. 
TABLE II-Treatment strategies and drug doses in systemic lupus erythematosus

\begin{tabular}{|c|c|c|}
\hline Indications & Drugs (dose) & Major side effects \\
\hline \multicolumn{3}{|l|}{ Symptoms: } \\
\hline Arthritis, pleurisy & NSAIDs, analgesics & $\begin{array}{l}\text { Peptic ulcers or bleeding, constipation, } \\
\text { addiction }\end{array}$ \\
\hline \multirow[t]{2}{*}{ Rashes } & Barrier creams & \\
\hline & Topical steroids & Skin atrophy, telangiectasia \\
\hline \multicolumn{3}{|l|}{$\begin{array}{l}\text { Modification of disease or disease } \\
\text { maintenance treatment: }\end{array}$} \\
\hline $\begin{array}{l}\text { Failure of symptomatic treatment or } \\
\text { after induction treatment }\end{array}$ & Prednisolone (5-15 mg/day) & $\begin{array}{l}\text { Osteoporosis, weight gain, diabetes, } \\
\text { infections }\end{array}$ \\
\hline Rash or arthritis & $\begin{array}{l}\text { Hydroxychloroquine } \\
(200-400 \mathrm{mg} / \text { day })\end{array}$ & Retinal damage, acne, rashes, nausea \\
\hline After induction; steroid sparing & Azathioprine $(1-2 \mathrm{mg} / \mathrm{kg} /$ day $)$ & $\begin{array}{l}\text { Infections, marrow suppression, } \\
\text { infertility, nausea, lymphoma } \\
(<5 \%)\end{array}$ \\
\hline \multicolumn{3}{|l|}{ Induction of remission: } \\
\hline $\begin{array}{l}\text { Life-threatening illness, nephritis, } \\
\text { cerebritis, fibrosing alveolitis, } \\
\text { major haematological } \\
\text { manifestations }\end{array}$ & $\begin{array}{l}\text { Oral prednisolone } \\
(0 \cdot 75-1 \mathrm{mg} / \mathrm{kg} / \text { day }) \\
\text { Methylprednisolone intravenous } \\
0.5-1 \mathrm{~g} \times 3 \text { pulses on alternate } \\
\text { days }\end{array}$ & $\begin{array}{l}\text { Osteoporosis, diabetes, infections, } \\
\text { avascular necrosis, psychosis } \\
\text { Steroid side effects, sudden death, } \\
\text { withdrawal syndromes }\end{array}$ \\
\hline $\begin{array}{l}\text { Nephritis (diffuse proliferative), } \\
\text { cerebritis (?), major haematological } \\
\text { manifestations }\end{array}$ & $\begin{array}{l}\text { Cyclophosphamide: oral } \\
1-3 \mathrm{mg} / \mathrm{kg} / \mathrm{day} \text {, or intravenous } \\
8-20 \mathrm{mg} / \mathrm{kg} \text { every } 4 \text { weeks with } \\
\text { mesna }\end{array}$ & $\begin{array}{l}\text { Infections, marrow suppression, } \\
\text { infertility, menopause, nausea, } \\
\text { cystitis, bladder carcinoma }\end{array}$ \\
\hline
\end{tabular}

\section{Treatment}

There is no specific treatment for systemic lupus erythematosus, but several drugs can modify the disease sufficiently for the patient's symptoms to be tolerable or vital organs to be protected from permanent damage. Side effects are common with these drugs and it is therefore essential to plan treatment strategies for each individual patient (table II). The potential benefit of each treatment regimen will be balanced by the side effects which, with cyclophosphamide, are almost inevitable. Certain precautions are mandatory. These include regular full blood counts for detecting possible marrow depression and giving mesna as a protection against cystitis or bladder carcinoma. Counselling and, if appropriate, sperm or ovum banking may be required as a precaution against infertility, which may be as high as $50 \%$ in patients treated with cyclophosphamide. It should also be remembered that one of the commonest causes of death in systemic lupus erythematosus is now infection, even though the five year survival has improved from a reported $50 \%$ in the 1950 s to greater than $90 \%$ in the 1990 s. $^{7}$ This implies that, although both diagnosis and treatment have improved, a substantial proportion of the deaths are likely to be due to immunosuppressive treatment.

\section{Prevention and treatment of symptoms}

Although the cause of systemic lupus erythematosus is unknown, certain factors such as ultraviolet light, hormones, and intercurrent infections lead to exacerbations of the disease. Simple measures such as using barrier creams; avoiding preparations containing oestrogen, such as the contraceptive pill; and prompt or prophylactic treatment of infections may prevent disease flares. Many of the common features are without long term sequelae and therefore can be treated symptomatically. The arthritis is rarely deforming, rashes usually heal without scarring, and pleurisy does not indicate parenchymal lung disease; such complications can be treated with simple measures such as anti-inflammatory drugs and analgesics.

\section{DISEASE MODIFYING DRUGS}

When these simple measures fail to maintain a tolerable quality of life in patients with limited disease it may be necessary to resort to drugs that modify the disease. Steroids have a potent anti-inflammatory effect, and even in low dose (5-10 mg of prednisolone) may control symptoms satisfactorily where simple measures have failed. There is a long tradition of the use of antimalarial agents in treating patients with a predominance of cutaneous and joint disease; they have symptomatic benefit as well as showing some effect on underlying disease activity. Azathioprine may also be used in this context, usually in doses and with precautions similar to those used in maintenance treatment (see below).

\section{INDUCTION AND MAINTENANCE TREATMENT}

Induction treatment is indicated in all potentially life threatening complications such as glomerulonephritis or neuropsychiatric disease. In systemic lupus erythematosus, true remission is rarely obtained, though the principles of treatment are analogous to those for leukaemia. The initial aim is for substantial suppression of the disease, which is then controlled by maintenance therapy.

\section{Steroids}

Although much of the recent literature has considered cytotoxic or immunosuppressive regimens, steroids remain the core treatment for the more serious manifestations of systemic lupus erythematosus. The starting dose is usually $0.75-1.0 \mathrm{mg} / \mathrm{kg}$; this is maintained for $6-10$ weeks and then reduced to a maintenance dose. The preparation most commonly used in the United States is prednisone; prednisolone, which is equipotent but with less mineralocorticoid effect, ${ }^{9}$ is more popular in Britain. Deflazocort, ${ }^{10}$ which was claimed to spare both bone and carbohydrate, is being increasingly prescribed in specialist units in some European countries, but it does not have a licence in Britain or the United States.

In the 1970s and 1980s there was much interest in the use of high dose $(1 \mathrm{~g})$ intravenous pulsed methyl prednisolone as a way of avoiding cumulative side effects from steroids and exploiting what seemed to be a "different" spectrum of pharmacological properties" of steroids given in this way. An early controlled study suggested that initial pulse therapy followed by oral steroids accelerated the response of proliferative nephritis in comparison with oral treatment alone, though the final outcome in terms of renal function did not differ between the two groups. ${ }^{11} \mathrm{~A}$ more recent study found no difference between intravenous pulse therapy and oral treatment with $100 \mathrm{mg}$ of prednisolone daily. It was concluded that there was no justification for the expense or potential dangers of pulse treatment -but there are many reports of individuals who responded to pulse treatment after being refractory to conventional oral therapy (reviewed in reference 9). There is now a consensus that pulse therapy is probably not indicated as routine treatment in systemic lupus erythematosus, though it may be held in reserve for special circumstances such as failure to respond to high dose oral steroids or rapid treatment of flares of disease when patients are already compromised by cumulative side effects. Alternate day steroids probably have no place in the management of acute disease flares, ${ }^{13}$ though they may be associated with fewer Cushingoid side effects when they are used in maintenance treatment.

\section{Cytotoxic drugs}

Cyclophosphamide and azathioprine have now become standard adjunctive treatment (with steroids) for the more severe manifestations of systemic lupus erythematosus. In renal lupus, several studies have shown that the incidence of renal failure is significantly lower in patients treated with cyclophosphamide plus steroids than with steroids alone (reviewed in referenes 9 and 13). ${ }^{14}$ Benefit has been shown for continuous oral treatment $(1-3 \mathrm{mg} / \mathrm{kg} /$ day) and for intermittent pulse therapy, $8-20 \mathrm{mg} / \mathrm{kg}$ once a month intravenously with mesna. There is no doubt that intravenous pulse therapy is associated with fewer side effects. To date 
there have been no published clinical trials comparing oral and pulse therapy, though Hahn is of the opinion that the oral regimens, though more toxic, are also more effective. ${ }^{10}$ Maintenance therapy can consist of a lower dose of oral cyclophosphamide $(0 \cdot 5-2 \cdot 0 \mathrm{mg} / \mathrm{kg} /$ day) or more widely spaced intravenous pulses (every 6-12 weeks). Cyclophosphamide is also used in treating cerebral lupus, but it is important to remember that there are no controlled studies showing benefit, and many units use steroids alone for central nervous system manifestatịons. ${ }^{15}$

Azathioprine is probably less effective than cyclophosphamide and is used mainly for its proved steroid sparing effects in maintenance treatment. It is used in a dose of $1.0-2.5 \mathrm{mg} / \mathrm{kg} /$ day and either started with steroids or added at a later date if the required maintenance dose of steroids is too high. One of the most feared side effects of azathioprine is lymphoma. These fears have been somewhat allayed by a study which found that in patients with rheumatoid arthritis treated rather eccentrically with very high doses of azathioprine (median $300 \mathrm{mg} /$ day) only $4 \%$ developed lymphoma compared with $2 \%$ of patients treated with other drugs. Because of its relatively low toxicity azathioprine may be preferred to cyclophosphamide for maintenance treatment even after induction with cyclophosphamide. ${ }^{16} \mathrm{~A}$ protocol used by our unit and other units ${ }^{17}$ is to give 3-6 pulses of $750-1000 \mathrm{mg}$ intravenous cyclophosphamide monthly with reducing doses of oral steroids and then switch to oral azathioprine $100-150 \mathrm{mg} /$ day plus a maintenance dose of steroids.

Cyclosporin is effective treatment for lupus, ${ }^{8}$ though its renal toxicity makes it difficult to monitor in patients with lupus nephritis. It is probably best reserved for patients unresponsive to conventional immunosuppression or for those in whom marrow toxicity is a particular problem. Methotrexate has a long history of rather intermittent use in systemic lupus erythematosus (reviewed in reference 18), though interest in the drug may have been reawakened by its well established use in rheumatoid arthritis. In one recent uncontrolled study of 17 patients, low dose weekly treatment resulted in improvement in 57\%, though with a rather high frequency $(71 \%)$ of toxic side effects. ${ }^{19}$ A potent steroid sparing effect was noted, however, and it was concluded that a controlled study was indicated.

\section{Plasmapheresis}

Plasmapheresis has long been used as adjunctive treatment for severe lupus, but a much needed controlled study was published only recently (reviewed in reference 20). Of 86 patients, all of whom were receiving conventional doses of steroids and cytotoxic drugs, 46 were additionally treated with plasmapheresis. There was no significant difference in the resultant serum creatinine concentration, though there was a trend towards a more rapid lowering of urinary protein excretion in the plasmapheresis group. The outcomes were similar and the study seriously questioned whether plasmapheresis was of any value in the treatment of renal lupus.

\section{Other treatments}

Other treatments that have been tried for specific manifestations of systemic lupus erythematosus have been reviewed by Miller. ${ }^{20}$ These include the use of synthetic androgens, with negative results; benefit from intravenous immunoglobulins for autoimmune thrombocytopenia; and a possible therapeutic effect of dapsone for bullous or discoid skin lesions. For patients with lupus anticoagulant or phospholipid antibodies, or both, and a history of thrombosis or recurrent abortions, low dose aspirin is now routine treatment. The place of steroids or anticoagulants is still controversial, though most units now recommend long term anticoagulation with warfarin for patients with a history of a major thrombotic event. The treatment of pregnant patients with recurrent fetal loss is more problematic. The now classic paper of Lubbe et al, which claimed protection from miscarriage by treatment with prednisolone ${ }^{21}$ has been challenged by more recent studies (reviewed in references 6 and 17), and low dose aspirin with careful monitoring may suffice. ${ }^{17}$

\section{Conclusion}

Suprisingly little has changed in either the diagnosis or treatment of systemic lupus erythematosus in the past 10 years, though there has been refinement of previous practice. The autoantibody tests have been standardised and most of the commonly used treatments have been examined in controlled trials. Encouragement by the improvement in survival has probably been tempered by the realisation that side effects of drugs have been an increasing problem both in mortality and morbidity. The trend is towards modification of established regimens to reduce side effects. At present, it has to be conceded that there is no evidence that any novel diagnostic test or treatment has fundamentally changed the management of systemic lupus erythematosus in recent years.

1 Harley JB. Autoantibodies. In: Systemic lupus erythematosis. Rheum Dis Clin North Am 1988;14:43-56.

2 Tan EM, Cohen ES, Fries JF, Masi AT, McShane DJ, Rothfield NF, et al. The 1982 revised criteria for the classification of systemic lupus erythematosus. Arthritis Rheum 1982;25:1271-7.

3 Ginzler EM, Antoniadis I. Clinical manifestations of systemic lupus erythematosus, measures of disease activity and long-term complications. Curr Opin Rheum 1992;4:672-80.

4 Marguerie C, Bunn CC, Beynon HLC, Bernstein RM, Hughes JMB, So AK, et al. Polymyositis, pulmonary fibrosis and autoantibodies to aminoacyl tRNA synthetases. Quant f Med 1990;77:1019-38.

5 Venables PJW. Overlap syndromes. In: Maini RN, Kalden JR, Smolen JS, eds. Rheumatology. London: Gower Medical Publishing (in press).
end

$6 \mathrm{McNeil} \mathrm{HP,} \mathrm{Chesterman} \mathrm{CN,} \mathrm{Krills} \mathrm{SA.} \mathrm{Immunology} \mathrm{and} \mathrm{clinical} \mathrm{importance}$ of anti-phospholipid antibodies. In: Dixon F, ed. Advances in immunology.
. Duluth: Academic Press, 1991:193-280.

7 Gladman DD. Prognosis of systemic lupus erythematosus and factors that affect it. Curr Opin Rheum 1992;4:681-7.

8 Levey AS, Lan S-P, Corwin HL, Kasinath BS, Lachin J, Neilson EG, et al. Progression and remission of renal disease in the lupus nephritis collaborative study. Ann Intern Med 1992;116:1 14-23.

9 Kimberly RP. Treatment: corticosteroids and anti-inflammatory drugs. In: Systemic lupus erythematosus. Rheum Dis Clin North Am 1988;14:203-21.

10 Deflazocort-a new glucocorticoid with bone sparing and carbohydratesparing properties: comparison with prednisolone. I Rheumatol 1981;8:78390.

11 Barron KS, Person DA, Brewer EJ Jr, Beale MS, Robson AM. Pulse methyl prednisolone therapy in diffuse proliferative lupus nephritis. $f$ Pediatr 1982:101:137-41.

12 Edwards JCW, Snaith ML, Isenberg DA. A double blind controlled trial of methyl prednisolone infusions in systemic lupus erythematosus. Ann Rheum methyl prednisolone

13 Hahn BH. Management of systemic lupus erythematosus. In: Kelley WN, Harris ED Jr, Ruddy S, Sledge C, eds. Textbook of rheumatology. 1993: 1043-56.

4 Steinberg $\mathrm{AD}$, Steinberg SC. Long-term preservation of renal function in patients with lupus nephritis receiving treatment that includes cyclophosamide versus those treated with prednisolone only. Arthritis Rheum 1991;34:945-50.

15 McCune WJ, Golbus J. Neuropsychiatric lupus. In: Systemic lupus erythematosus. Rheum Dis Clin North Am 1988;14:149-67.

16 Silman AJ, Petrie J, Hazelman B, Evans SJ. Lymphoproliferative cancer and other malignancy in patients with rheumatoid arthritis treated with and other malignancy in patients with rheumatoid arthritis treated with
azathioprine; a twenty year follow-up study. Ann Rheum Dis 1988;47: 988-92.

17 Vyse TJ, Walport MJ. Connective tissue diseases: advances in diagnosis and management. Br f Hosp Med 1993;50:121-32.

18 Lieberman JD, Schatten S. Treatment: disease-modifying therapies. In Systemic lupus erythematosus. Rheum Dis Clin North Am 1988;14:223-43.

19 Wilke WS, Krall PL, Scheetz RJ, Babiak T, Danoa T, Mazanec DJ, et al. Methotrexate for systemic lupus erythematosus: a retrospective analysis of 17 unselected cases. Clin Exp Rheumatol 1991;9:581-7.

20 Miller ML. Treatment of systemic lupus erythematosus. Curr Opin Rheum 1992;4:693-9.

21 Lubbe WF, Palmer SJ, Butler WS, Liggins GC. Fetal survival after prednisolone suppression of maternal lupus anticoagulant. Lancet 1983;i: $1361-3$. 